\title{
SIGNIFICADOS VISUALES EN EL BURLADOR DE SEVILLA Y CONVIDADO DE PIEDRA DE TIRSO DE MOLINA
}

\author{
Rafael MAESTRE
}

\begin{abstract}
Resumen
Desde un punto de vista escenotécnico, a lo largo del presente artículo se puede comprobar cómo Tirso de Molina tenta el drama sin solución de continuidad, a través de unas discordancias con las teorías poético-dramáticas de su momento: sólo mantiene la unidad de acción y apenas procura la de tiempo, en pro de una escena concebida como un todo unitario y múltiple, a la vez, por medio de la escena fija o base. Se comprueba también, mediante una aproximación reconstructiva de la puesta en escena de su estreno en el corral de comedias, que esta tarea del mercedario es un modelo de destreza en la técnica dramática, pues son los significados visuales los que determinan los episodios y sus secuencias, así como la fórmula estructural constante sobre la que descansa el quehacer dramático.
\end{abstract}

\begin{abstract}
Throughout this article, it is possible to see, from a staging craft point of view, how Tirso de Molina experiments with drama without interruption in the above mentioned play. This is achieved by means of certain conflicts with the current poetical and dramatical theories of is age: he just keeps to the unity of action and he hardly goes by the unity of time so as to create a stage which is conceived as a whole, unitary and multiple at once, and this is done through the fixed stage. It can also be seen, by means of a reconstructive approach to its premier in the open air theatre or corral de comedias, that the mercedary's taks is a model of skill in stagecraft, as the visual meanings really determine their episodes and sequences, as well as the constant structural formula on which the dramatic is based.
\end{abstract}

Tirso de Molina!, en El burlador de Sevilla y convidado de piedra, tenta la escena sin solución de continuidad; cuanto menos en lo referente al aspecto escenotécnico. Sin embargo, no sucede así con los personajes y sobre todo con el Burlador, para

1. La inexistencia del «cuaderno de dirección» o memoria de apariencias y el panorama de confusa fiabilidad que presentan los distintos textos de las ediciones primitivas de El burlador de Sevilla y convidado de piedra: la de Barcelona de 1630, la de Zaragoza anterior a 1654, etc., obligan a una elección. Para el 
quien las entrejornadas o entreactos (aun a pesar de ir intercalados de jácaras, mojigangas o entremeses) son soluciones de continuidad en que él se desenvuelve sobre una premisa para la que se da una cierta pluralidad o acumulación de acontecimientos. Tal tentativa supone un afán de ampliar el perímetro bloqueado del espectáculo establecido por sus antecesores, como señala Rojas ${ }^{2}$, al igual que lo habian intentado, aunque en otros aspectos, algunos de sus coetáneos como Alarcón o Claramonte ${ }^{3}$.

Unido al grupo de dramaturgos heterodoxos que se instalan en las vías abiertas por el resquebrajamiento de las unidades y reglas aristotélicas ${ }^{4}$ y la recuperada de lugar por G. C. Scalígero ${ }^{5}$, así como su sistematización en el panorama español,con sus contradicciones, por el Pinciano ${ }^{6}$, el mercedario se inhibe de la de tiempo,no obstante alcanza la uniformidad en el juego día-noche, mantiene la de acción y procura conservar la dogmatizada por el humanista italiano.

restablecimiento del texto de Fray Gabriel, sigo la preparada por Américo Castro (Tirso de Molina: $E l$ vergonzoso en palacio. El burlador de Sevilla y convidado de piedra, (10 ed.), Madrid, 1975.), sin perder de vista la de Xavier C. Fernández (Tirso de Molina: El burlador de Sevilla y convidado de piedra, Madrid, 1982), así como su artículo («En torno al texto de El burlador de Sevilla y convidado de piedra», en «Segismundo», núms. 9-14, Madrid, 1969-71. Numeración errada, pues cuando se autocita, lo hace para con el número 5-7 de la mencionada revista). También contemplo las de Ignacio Arellano (Tirso de Molina: El burlador de Sevilla, Madrid, 1989) y Alfredo Rodríguez López-Vázquez quien, como se aprecia, sostiene la autoría de Andrés de Claramonte (Andrés de Claramonte: El burlador de Sevilla, Kassel, 1986), aunque no enmiendo por ellas. Las acotaciones, si cabe, son más imprecisas y frágiles que la fiabilidad del texto dramático, e, incluso, algunas de ellas no están en correspondencia sincrónica entre la palabra y la acción, por lo que en este caso lo afirmado y ratificado por el verbo del actor es su mejor acotación. Por consiguiente, requiriendo el auxilio de la tipología escenotécnica del corral y fuera de él, el verbo nos configura el cuaderno de la escenificación.

2. «¿Qué harán los que vinieren, / que no sea cosa hecha? / ¿Qué inventarán que no esté / ya inventado? Cosa es cierta. / Al fin la comedia está / subida en tanta alteza, / que se nos pierde de vista; / plegue a Dios que no se pierda», en Agustín de Rojas Villandrando: El viaje entretenido, ( ${ }^{\mathbf{a}}$ ed. expurgada en 1611), (ed.de J.P.Ressot), Madrid, 1972, págs.154-55.

3. Lope de Vega en su tragicomedia famosa Lo fingido verdadero, al dedicarla a Fray Gabriel, además de ensalzarle, aprovecha para criticar a otros dramaturgos contemporáneos: «... a pesar de los que envidian sus obras, que tantos bien intencionados califican; haciendo elección de historia divina, así por su profesión como por haberlas escrito tan felizmente, escureciendo los que se valen de Edipos y Tiestes, que mejor dijera de los caballos y carpinteros, por quien...», en Lope de Vega: Obras escogidas, ( $3^{\mathrm{a}}$ ed.), tomo III, Madrid, 1967, pág. 166. M. Menéndez y Pelayo explicita la crítica: «De paso se traslucen alusiones satíricas a otros poetas que se valen de caballos y carpinteros. La de los caballos ha de referirse al gran plagiario Andrés de Claramonte, que tenía la manía de introducir en sus comedias desafíos a cabaIlo por el patio (...) Lo de los carpinteros puede ser un dardo contra la maquinaria usada en El Anticristo de Alarcón(representado en 1618)...", en Estudios sobre el teatro de Lope de Vega, (ed. de A.Bonilla San Martín), tomo l, Madrid, 1919, pág. 250. El abuso de la maquinaria y el añadir espectacularidad a la representación, tanto por Alarcón como por Claramonte, aunque censurable, no deja de ser un intento de intensificar la verosimilitud en un panorama en el que las convenciones escénicas del corral se habían mantenido apenas sin evolución, desde el año 1575 al 1600.

4. Contenidas en La Poética, a la que se circunscribían y suscribían buena parte de los humanistas del Alto Renacimiento. Ceñidos a ella, por su redescubrimiento y por el hilo vitruviano, estos eruditos devenían hacia una cierta objetividad. Ver, Aristóteles: Obras, (ed. de SAMARANCH, F. de P.), Madrid, 1964, págs. 83 y ss.

5. Es G. C. Scalígero quien convierte en dogma la unidad de lugar, descubierta en el filósofo de Estagira, según entiende S. D'Amico: Historia del teatro dramático, vol. 2, México, 1961, pág. 15.

6. La corriente de las teorías del heleno en España encuentra a uno de sus más señalados representantes en LÓPEZ PINCIANO, A.: Philosophía antigua poética, (ed. de A. Carballo Picazo), vol. I, reim., Madrid, 1973, págs. 239 y ss. 
Todavía sin impostarla a las características del corral con su funcionalidad polivalente, a donde sabe destinada la pieza, nuestro autor concibe su puesta en escena como un todo unitario y múltiple por medio de la escena fija o base, que una vez impostada en el referido marco escénico, permite que se conjuguen multiplicidad y polivalencia, y se proyecten y desarrollen las vicisitudes de la "comedia famosa» ${ }^{7}$ en el criterio unitario.

La escena fija o base no es la arquitectura o teatro que se levanta al fondo del tablado del corral; es, en su concepción, una escena «de marina»: riberas o playas de Nápoles, Tarragona, Sevilla -río-, etc. Por tanto, es la que queda, con parciales variantes escenográficas, para toda la duración del espectáculo, donde los incidentes previstos para dinamizar la acción dan pretexto a la realización de efectos particulares: la autocomplacencia del poder en el diálogo Rey-D.Gonzalo, el incendio de la capilla del Comendador, etc. Bajo este prisma, su trabajo presenta un talante novedoso, si no innovador, poco usual, ya que se vale de dos tipologías diferentes fundidas y bien armonizadas: integra escenas de bosque en la marina, buscando de este modo la escena "naturalística»".

De los cuatro episodios, de «Isabela», «Tisbea», «Aminta» $\mathrm{y}$ «Estatua», que estructuran la pieza, particularmente dos, los «de Tisbea» y «de Aminta», arrojan elementos integrantes del denominador común que los caracteriza.

La jornada primera se inicia con el episodio «de Isabela» y el transcurrir de su acción o primer acontecimiento, o secuencia, se lleva a cabo en los umbrales interiores del palacio del rey de Nápoles"; para la que el decorado colocado en la fachada interior del corral, teatro de él, representa una puerta en el primer hueco derecha del tablado ${ }^{11}$, otra en su opuesto hueco izquierda, pero adornada (como señalan los versos

7. Tirso de Molina: El vergonzoso en palacio. El burlador de Sevilla..., (ed. de A. Castro), ..., op. cit., pág. 147.

8. Tipo de escena, propia del escenario palaciego y debida a la perspectiva, que tiene el primer antecedente en Italia con Girolamo Genga, en la ejecución del aparato escénico que probablemente llevó a cabo en Pesaro, en 1525, y en la retoma que de él hizo Serlio para tipificar la escena satírica. La traza de Genga, en gran medida, pretende fundir tipológicamente los géneros al uso: satírico, cómico, trágico; pero es Buontalenti quien da el paso casi definitivo, cuando en el teatro de los Uffizi, en 1585-86, ponga en escena L'Amico Fido. El totalmente definitivo lo dará Alfonso Parigi el Joven con Flora, en 1628. Tirso debió de ver o tener noticias muy fidedignas del trabajo en España del escenotécnico italiano Fontana-conocedor de los avances buontalentianos-para la escenificación de La gloria de Niquea; de ahí, quizá, extrajese el criterio que ahora aplica a su comedia. Además de que en la entrada en escena de Isabela-en la jornada tercera, en las playas de Tarragona-semeja a Europa, según comenta Tisbea que la recibe ( «iSois vos la Europa hermosa? / ¿Que esos toros os llevan?», en Tirso de Molina: $E l$ vergonzoso... El burlador..., op. cit., pág. 230, n. 374.), guarda muy estrecha relación con la aparición de Abril en la obra del conde («Tiraba un toro su florida máquina (...) a la ninfa entre los puros candores de su belleza (...) la juzgaron los ojos por la doncella Europa», en Villamediana: Obras, (ed, de J. M. Rozas), Madrid, 1980, pág. 364. La gloria de Niquea de Juan de Tarsi, conde de Villamediana, fue estrenada en representación nocturna, durante la primavera de 1622 . Sobre aspectos de su escenificación, trata mi trabajo: Valores visuales de actor y actuación, Murcia, 1996, págs. 4-14.

9. «iAh de palacio!», «sino en Nápoles también, / y en el palacio real», «te incitó, que en mi palacio, / ...profanases sus umbrales», en Tirso de Molina: El vergonzoso... El burlador..., op. cit., págs. 148, 15l, 154.

10. «Izquierda y derecha, las del espectador»... «por aquí / podrás salir más seguro», «a ese cuarto os retirad», «retirada en esa pieza», en Ibídem, págs. 148, 150, 153. 
304-06 de la segunda secuencia de este primer episodio), en la parte superior de sus jambas y dintel, por hojas de olmo" y el vestuario o hueco central permanece cerrado ${ }^{12}$. Se impostan, en el primer corredor, una torre ${ }^{13}$ en el balcón de la derecha, un esquife o nave con velamen ${ }^{1+}$ en el de las apariciones o central y vegetación trepadora ${ }^{15}$ en el de la izquierda.'Toda la decoración de este primer acontecimiento o secuencia se presenta «a vista»; es decir, todos los elementos están al descubierto, a excepción del vestuario que presenta las puertas o cortinas cerradas.

La segunda secuencia de este episodio tiene lugar en el aposento palaciego del duque Octavio, también en Nápoles, y el vestuario abierto muestra una cama adereza$\mathrm{da}^{16}$, manteniéndose el resto de las apariencias o elementos decorativos igual que en el acontecimiento anterior.

Dentro de esta misma jornada, el segundo episodio o «de Tisbea» sucede en un aldea de pescadores en las playas de Tarragona ${ }^{17}$, donde se ve a dicha pescadora sobre una roca ${ }^{18}$ en el vestuario abierto, desde el que comienza su parlamento o monólogo de presentación, con el que irá abarcando el tablado, para luego volver a la roca, o hacer mención de ello ${ }^{14}$, y lanzar el anzuelo; acción que interrumpirá para describir la peripecia del naufragio de D.Juan. Lo realizado por Tisbea no se corresponde con la acotación - «(...y sale Tisbea, pescadora con una caña de pescar en la mano)»-20, pues no sale, como sabemos por los versos 657-59 del coloquio que tiene con Catalinón, D.Juan, Coridón y Anfriso; o sea, no entró en escena sino que apareció sobre la roca, al mostrarse esta apariencia en el vestuario.

El resto de las apariencias no ha sufrido apenas variación con respecto al episodio «de Isabela», y aunque Tisbea hable de pajas y cañas ${ }^{21}$ referentes al hueco izquierdo del tablado, también confirma su decoración de olmos 22 ; únicamente el esquife del balcón de las apariciones, al que se le ha imprimido movimiento ${ }^{23}$, ahora enseña su gavia.

11. «...Cuando salieron / por esa vecina puerta», «entre los pies de esos olmos / que coronan del palacio / los chapiteles hermosos», en Ibídem., págs. 153, 159.

12. «...tu cuarto, gran señor», en Ibídem., pág. 149.

13. «...a esa mujer llevad presa / a una torre», en Ibídem., pág. 154.

14. «...la espumosa orilla / del mar de Italia», en Ibídem., pág. 151.

15. «¿Atreveráste a bajar / por ese balcón?», «Baja, pues, por el balcón», «por el balcón de la huerta / se arroja desesperado», en Ibídem. págs.151, 152, 153. Coloco el huerto en el lado izquierdo, siguiendo la convención de las representaciones profanas en la época renacentista, instaladas todavía en las cortiles, donde el escenario se ubicaba a la derecha del jardín.

16. «¿Tan de mañana, señor, / te levantas?», «no apetece cama blanda, / entre regalada holanda, / cubierta de blanco armiño», en Ibídem., pág. 155.

17. «De cuantos pescadores / con fuego Tarragona / de piratas defiende», en Ibídem., pág. 163.

18. «Estando, amigos, pescando / sobre este peñasco, vi / hundirse una nave alli», en Ibídem., pág. 172.

19. «Quiero entregar la caña / al viento», en Ibídem., pág. 165.

20. Ibídem., pág. 161.

21. «Obeliscos de paja / mi edificio coronan», «Ven, será la cabaña / ...tálamo de nuestro fuego. / Entre estas cañas te esconde», en Ibídem., págs. 163, 184

22. «...pues que con (los) ramos verdes / que de los olmos corta, / mis pajas amanecen», en Ibídem., pág. 164.

23. «...una nave, / antes que el mar la sorba / ...hace las velas cola, / ...y dejó al viento / la gavia», Ibídem., págs. $165,166$. 
Se abre la jornada segunda con el interior del palacio del rey D. Alonso en Sevi$11 a^{2-4}$, para luego convertirse en plaza o plazuela del tal palacio o alcázar, a donde concurren calles ${ }^{25}$. La variante que presenta el decorado para con la jornada anterior, estriba en que el vestuario a manera de salón regio, revela al rey en un sitial ${ }^{26}$ en donde arranca el diálogo con D. Diego, que, después, cerrado contribuye a figurar las mencionadas plazuela y calles. Junto a este cambio surgen nuevos indicadores verbales sobre el balcón del huerto y la puerta decorada de olmos, que señalan la existencia de media reja en la parte inferior del balcón y media celosía en la parte superior de la puerta ${ }^{27}$, unidas a los elementos ornamentales presentes que ya poseían impostados a vista; la nave está como antes del naufragio y la reja se sitúa en el balcón, porque el billete que entrega $\mathrm{D}^{\mathrm{a}}$ Ana, no llega de mano a $\mathrm{D}$. Juan sino por el aire ${ }^{28}$.

Con el primer acontecimiento del episodio "de Aminta», se cierra esta jornada que centra su acción en Dos Hermanas ${ }^{29}$, aldea contigua a Sevilla.Todas las apariencias abiertas presentan la misma decoración anterior, salvo en los últimos incidentes que permaneció cerrado el vestuario, que ahora abierto enseña árboles o arbustos continuadores de una alfombra florida ${ }^{30}$ que se ha instalado en el tablado.

La tercera jornada, continuación del episodio anterior, nos trae un nuevo o segundo acontecimiento en la misma decoración, e igualmente abierta, sin que experimente ninguna transformación, como señalan los versos: «Ya viene, no me resisto, laquí me quiero esconder» ${ }^{31}$ de Batricio, pero cuya acción no consuma. Sólo como conforme avance éste, el acontecimiento, va a significar el que el vestuario trueque árboles y alfombra por cama aderezada ${ }^{32}$, y aparezca como en la primer jornada, pero

24. «Mi enojo sea / en el destierro de Sevilla», «Yo os casaré en Sevilla», en Ibídem, págs. 188 y 189-90.

25. «...que hoy nos juntamos los dos / en Sevilla.... Quien pensara, / duque, que en Sevilla os viera!», «Mas llegándola a habitar, / es... corta cualquier alabanza/que à Sevilla queréis dar», «¿Qué hay de SeviIla?...Está ya/toda esta corte mudada», «síguele el paso al marqués, / que en el palacio se entró», "pues salí de la plazuela», «Voces siento / en la plaza del Alcázar», en Ibídem., págs. 192, 193, 194, 198, 199, 211. La edición de X. C. Fernández presenta una variación, con respecto al verso tercero de esta nota, ya que coloca en labios de Octavio los versos 1166 y ll67, según la página 115 . En la que seguimos, van colocados en los de D. Juan, al mismo tiempo que acoge mayor número (vv. I18-12l, pág. 192), lo que supone una traspolación de interlocutores. La del profesor Fernández, aunque en este caso no se deba a errata, no está exenta de error, como sucede con el verso 2592 que lo atribuye a D. Juan cuando realmente corresponde a Octavio.

26. El monarca solicita una silla, en su diálogo con D. Gonzalo, en la jornada primera, intercalado en el episodio de Tisabea, con paisaje piscitorio, donde se describe Lisboa ( Dadme silla», pág. 175). El empleo de esta pieza del atrezzo da motivo para interpretar que el rey, ya en su propio salón, haga uso del sitial. También es usual su empleo entre los dispositivos escénicos del corral; ver D. Castillejo y otros: El corral de comedias, Madrid, 1984, pág. 117.

27. «...por esa reja, sin ver», «¿Veis aquelia celosía? / ...Ya la veo», en Tirso de Molina: El vergonzoso... El burlador..., op. cit., pág. 201, 207.

28. «A mí el papel ha llegado / por la estafeta del viento», en Ibídem, pág. 199.

29. «Venga tan gran caballero / a ser hoy en Dos Hermanas», en Ibídem, pág. 215.

30. «Sobre esta alfombra florida», en Ibídem, pág. 203.

31. Ibídem, pág. 219.

32. «Mira que vendrá tu esposo: / entra a desnudarte, Aminta», «que nadie en la casa pisa / de un desposado, tan recio», "Quiero llegar a la cama», «En mi aposento a estas horas?», en Ibídem, págs. 221, 222, 224. El aderezo de la cama se repite el mismo que el de la del duque Octavio, puesto que ahora, aunque de rústicos, se utiliza el más rico ajuar para la desposada en su gala nupcial. 
haciendo el papel de estancia de Aminta, aunque previamente al abrir de esta apariencia, durante dos diálogos permanezca cerrado.

Acabado el episodio, la escena vuelve a mudarse en la misma que fue para el segundo de la jornada primera: la aldea de pescadores en las playas de Tarragona; por lo que en el vestuario se ha sustituido la cama por la roca, hallándose todos los elementos restantes igual, a vista, e incluso a la nave se le imprime movimiento como en el naufragio de D. Juan ${ }^{33}$. En este ambiente Isabela y Tisbea se refieren sus cuitas y nos indican el traslado de la acción a Sevilla ${ }^{34}$.

Ya en la ciudad bética ${ }^{35}$, como sucediera al principio de la jornada segunda, a diferencia con ésta, se precisa el discurrir de la pieza en el interior de una iglesia, en la capilla con tumba de D. Gonzalo ${ }^{36}$, que se metamorfosea en el interior del aposento del Burlador ${ }^{37}$. Ningún ornamento ha variado, exclusivamente el vestuario permanece cerrado, y el atrezzo -mesas y sillas-, implantado en la «zona fuerte ${ }^{38}$ del tablado, es el indicador del lugar y del nacimiento de la primera secuencia del episodio «de la Estatua» ${ }^{39}$, el cual, una vez retirado ${ }^{40}$, dará distinta configuración a este espacio.

$\mathrm{El}$ altar o ara con luces ${ }^{41}$ y la tumba apilastrada que se vio en la capilla, al abrirse en este momento el vestuario, lo figura del mismo modo que comenzó la jornada segunda: salón regio con sitial en palacio ${ }^{42}$. Tirso repite el mismo juego que en dicha jornada: conversión, por cierre del vestuario, en plaza o plazuela del tal palacio o alcázar a donde concurren calles ${ }^{43}$, que a la par hace de atrio o fachada de la iglesia ${ }^{44}$. Aquí se acoge la segunda secuencia del episodio «de la Estatua», en el espacio resultante de abrirse el vestuario y exhibir repetida la capilla con altar o ara y tumba, mutación en interior del sacro recinto.

La estatua 0 «bulto» ${ }^{45}$ de $\mathrm{D}$. Gonzalo no está erguida sino yacente, quien a manera de altorrelieve descansa sobre la losa del sarcófago o sepulcro, como explican

33. «¿Dónde estamos ahora? En Tarragona», «El mar está alterado / y en grave temporal./ (Viento sur corre.). / El abrigo han tomado / las galeras, ...duquesa, de la torre / que esta playa corona», en Ibídem, pág. 218. El fragmento que figura entre paréntesis, lo tomo de la edición de X. C. Fernández, pág. 150.

34. «A Sevilla llévanme a ser esposa», «Ven en mi compañía», en Ibídem, págs. 230, 231.

35. «Dice que viene Isabela», en Ibídem, pág. 232.

36. «La iglesia es tierra sagrada», «Qué sepulcro es éste ...Aquí / don Gonzalo está enterrado», en Ibídem, pág. 233 .

37. «¿Dónde me tienes posada? ...En la calle oculta», «Quiero apercibir la pieza, / que vendrá a cenar don Juan», en Ibídem, págs. 233, 234.

38. Es el punto de intersección de unas líneas imaginarias: una, central perpendicular que remata en el foro o eje de la senoide, y otra que lo corta, paralela al proscenio, recorriendo de izquierda a derecha el tablado. Esta zona está más alejada del foro que del proscenio.

39. «Puestas las mesas están», «Siéntate», «Siéntate, Catalinón», en Ibídem, págs. 234, 237.

40. «iHola! Quitad esa mesa», en Ibídem, pág. 240.

41. David Castillejo y otros: El corral..., op. cit., pág. 90.

42. «...que quiero que en palacio / asista», en Tirso de Molina: El vergonzoso... .El burlador..., op. cit., pág. 243.

43. «...¿no lo sabéis, / siendo del alcázar vos?», «En el alcázar tenéis / bodas», «Venid... y a un cuarto del rey saldréis», «Cómo el rey te recibió?», en Ibídem, págs. 246, 247.

44. «Ya está cerrada la iglesia», en Ibídem, pág. 249.

45. «Bulto ...significa algunas vezes la efigie puesta sobre la sepultura de algún príncipe, y algunas vezes la mesma tumba cubierta. Figura de bulto, la que hace el entallador o escultor; por ser figura con cuerpo...», en Cobarruvias: Tesoro de la lengua castellana o española, (ed. fac.), Madrid, 1984, pág. 245. 
los versos de Catalinón: « ¡Ay de mí! Tenme, señor, / porque de la capa me asen» ${ }^{46}$; es la propia tumba la que ejecuta el «rol» de mesa con sus correspondientes patas ${ }^{47}$, a la que dos enlutados pajes adosan sillas. Al levantar y colocar la tumba en la «zona fuerte» del tablado, donde ha tenido lugar la macabra cena, ha quedado libre la trampa del escotillón para el descenso y desaparición de D. Juan muerto y D. Gonzalo, no sin que antes éste por medio de señas ${ }^{48}$ haya atendido la petición del Burlador de retirar la mesa-tumba y sillas ${ }^{40}$.

Como se aprecia, la acotación «(Húndese el sepulcro, con don Juan y don Gonzalo, con mucho ruido) $\gg^{50}$ no se corresponde ni sincroniza exactamente con la acción, pues ya antes de su colocación, inmediatamente posterior al verso 974, se han producido los efectos de humo y fuego, a través del escotillón, que van creciendo, especialmente este último, hasta parecer que "Toda la capilla se arde»" ".l. Una vez cerrado el vestuario, con distinta ocasión es reabierto para presenciar, una vez más, el interior del salón regio ${ }^{52}$; lugar en el que el rey acordará bodas entre los distintos ofendidos.

Tirso ha hecho que, desde el comienzo hasta el fin de la obra, todas las apariencias se hayan presentado a vista sin variarlas, a excepción de los determinados movimientos y suspensos impresos a la nave, y no las ha cubierto o cerrado en ningún momento, por lo que todo el cambio de decoración lo ha supeditado al vestuario.Este elemento del foro, en su versatilidad ${ }^{53}$, ha permitido los distintos desplazamientos de los lugares de la acción. En correspondencia a este comportamiento versátil ha auna-

46. Tirso de Molina: El vergonzoso... El burlador..., op. cit., pág. 249. La petición del rey (vv. 617-24, pág. 2L3), inmediata a la muerte del comendador, de que se le haga un bulto con una cartela, no puede ser de estatua erguida porque implicaria el alzarla sobre una peana o basa o probable tarima del vestuario, donde su lienzo frontal llevaría grabada la leyenda que solicita el monarca. Desde esa altura difícilmente podría producirse el juego que nos indica Catalinón; además, el sarcasmo de los ademanes contorsionados del gracioso queda subrayado, si se hace semincorporándose la Estatua, desde su posición tendida, para asirle los bajos de la capa. Hecho desde lo alto, en los hombros, el juego queda inerte.

47. «Para cenar / es menester que levantes / esa tumba», «levantaré esos pilares», "Mesa de Guinea es ésta», en Ibídem., pág. 250. Versos que confirman la fortaleza del sepulcro para que el peso del actor pueda descansar en su losa. También son ratificados por los versos 906, 907 de la misma página.

48. Acciones físicas que han completado el verbo (v. 945, pág. 252), en repetición de un juego anterior, acompañadas por el presagio, también seña, de la canción en el «desde dentro» (vv. 930-33, pág. 25l.).

49. «...haz que levanten / la mesa», en Ibídem., pág. 250.

50. En ningún momento, el texto en acción expresa ruidos. Aunque su uso en el corral fuera frecuente, no se hacía para las entradas o descensos en las sepulturas, sino para las salidas o ascensos; de los que son típicos ejemplos algunas acotaciones cervantinas: «(... debajo suenan cohetes y hágase ruido), (Sale el cuerpo amortajado con rostro de muerte), (Se arroja el cuerpo en la sepultura), (arrójase Marquino en la sepultura», en Miguel de Cervantes: El cerco de Numancia. Teatro completo, vol. II, Barcelona, 1966, pág. 70. Tampoco hay hundimiento de sepulcro, porque como mesa fue retirado de la «zona fuerte», a fin de no impedir parte de la visibilidad de la lucha-abrazo y las bajadas al foso del tablado.

51. Tirso de Molina: El vergonzoso... El burlador..., op. cit., pág. 253.

52. «Entre luego, y avisad», en Ibídem., pág. 253.

53. Las cortinas o puertas del escenario se sobreponen a la línea de conexión entre el tablado y el foro (fachada interior del teatro), y es a partir de esa línea de hacia el fondo del hueco, en su parte trasera, donde las apariencias se inscriben cerradas por un forillo. La apertura y cierre de éstas facilita los cambios de elementos. El mismo escotillón ayuda a ello, ya que se encuentra en este espacio, y su parte más próxima al tablado es tangente a dicha línea de conexión. En el asunto que nos ocupa, una prolongación imaginaria de la bisectriz de la eclíptica atravesaría perpendicularmente la transversalidad del sepulcro. 
do el acaecer del día o la noche; así, cuando ha estado abierto, se han desarrollado las escenas del día y sus gradaciones crepusculares: madrugada, amanecer, ... y cuando lo ha hecho cerrado, con la neutralidad que esta actitud supone al tablado-foro, la de noche y las suyas: atardecer, cerrada, ...

En la uniformidad de esta regla subjetiva, de noche y sus gradaciones, o con el vestuario cerrado, han sucedido las siguientes vicisitudes encerradas en los versos: noche (vv. 0-190), en la jornada primera; atardecer (vv. 81-376), noche (vv. 377-632), en la jornada segunda; noche (vv. 10l-93), noche (vv. 474-687), atardecer (vv. 788836), noche (vv. 837-946), en la jornada tercera ${ }^{54}$. Las restantes corresponden al día y las suyas. Una de ellas se ejemplifica en la madrugada, cuando el futuro conde de Lebrija se dispone ${ }^{55}$ a recabar el acto de seducción de Aminta, que lleva a término sobrepasadas las doce horas, en los anuncios del lucero matutino, el planeta Venus, de disipar sus fulgores ${ }^{56}$.

$\mathrm{Al}$ arbitrar de este modo claridad-oscuridad y cronología-tiempo natural, nuestro fraile se toma licencia, sin desconectarse por ello de la uniformidad establecida, por tanto confirmando la regla, en su punto excepcional: la muerte del Burlador, quien ha pedido morir de día, en la iglesia ${ }^{57}$. Única de las solicitudes atendida para su agonía y a la que el presagio fatídico del cercano sucumbir lo marcan los signos, ademanes y verbo, con el comendador de Calatrava, tras la segunda cena (vv. 946-48). En ella se repiten los mismos signos que en la primera (vv. 621, 622 y 644), como expresan las palabras de Catalinón en su narrativa final al monarca, «acabando de cenar, / entre mil presagios graves» ${ }^{58}$, sobre las acciones de levantar la mesa y después darse las manos, porque la pausa que media entre una acción y la siguiente, hace de transición o paso temporal a la madrugada o alba, por lo que es día cronológico, por más que no exista luminosidad natural, total claridad. Además, metafórica y realmente está iluminada: el incendio invade toda la capilla.

La escena fija o base también ha expuesto, en razón directa a la versatilidad del vestuario, su multiplicidad en sus restantes elementos, como bien tipifican dos de ellos: la torre y el balcón. La primera ha hecho esta función para palacio napolitano del duque Octavio; para ciudades de Nápoles, Tarragona, Lisboa, Dos Hermanas; para alcázar regio e iglesia de Sevilla. El balcón, lo ha sido de huerta o jardín en palacios, napolitano, portugués, sevillano; de cabañas aledañas en Tarragona y Dos Hermanas; de vivienda en Sevilla y de iglesia en la misma ciudad.

Singularmente en dos circunstancias, el madrileño recurre a la polivalencia del corral (gracias al verbo del actor se produce el cambio de lugar y no por la versatilidad del vestuario, que permanece cerrado), pero siempre en muy estrecha unión a la facultad múltiple de la escena referida. Una, al hacer que la torre, siendo alcázar regio, adquiera credibilidad momentánea de fortaleza de Triana ${ }^{59}$. Otra, al traducir la plaza del palacio en plazuela de iglesia.

54. Los atardeceres, particularmente, vienen significados por el cambio de indumentaria.

55. «...y ya las cabrillas / entre racimos de estrellas / el polo más alto pisan», en Ibídem, pág. 224.

56. «En mi aposento a estas horas? ...(Estas son las horas mías)», en Ibídem, pág. 224.

57. «La iglesia es tierra sagrada ...Dí que de día me den / en ella la muerte», en Ibídem, pág. 233.

58. Ibídem, pág. 255.

59. Versos 716 y 826-28, en lbídem, págs. 243, 247. 
Los huecos laterales del tablado los ha utilizado alternativamente para entradas y salidas, pero manteniendo una convención estable, en la que han estado en correlación los distintos lugares de la acción con el juego escénico; por ejemplo, y unicamente por lo que afecta a la primera jornada, las cuatro huidas, aunque propiamente como tales son dos, han tenido lugar por el lado izquierdo, tanto en su parte baja (hueco del tablado que oficia de puerta de jardín o huerto o cabaña piscitoria) como en su parte alta (balcón de él o de la misma). De ellas, dos son aéreas, a nível del primer corredor, y dos terrestres, a ras de las tablas.

La primera, la de $\mathrm{D}$. Juan desde el balcón del palacio regio napolitano, al que accedió por la puerta del jardín, donde el actor ademanó la caída hacia el lado izquierdo, acentuando más la sugerencia o identificación como lugar o espacio de huerto. La cuarta, o segunda aérea, la del conato o intento de suicidio de Tisbea desde el balcón de su cabaña, en un ambiente no incendiado real ${ }^{60}$. En ella, la actriz repite el mismo desplazamiento que realizó el actor en la primera; por más que el ademán de arroje se hace ahora hacia la derecha, a fin de dar verosimilitud al espacio mar, ya que contiguo a este hueco del corredor, en el central, se encuentra el esquife. La segunda, o primera terrestre, la del duque Octavio, sucede a través de la puerta del jardín ${ }^{61}$ de su palacio napolitano. La tercera, o segunda terrestre, la lleva acabo el Burlador cuando entra en la cabaña de la pescadora, lo que significa una salida de escena por esta puerta, pues sabremos después, por boca de la infortunada, que escapó a caballo desde allí.

La dinámica del movimiento de los actores se mantiene compensada completamente -por lo que atañe a su juego en el tablado- en una constante pendular muy cerrada, cuyos puntos de nacimiento afloran de los huecos laterales y su eje central se fija en una línea imaginaria que saliendo del vestuario, divide a la escena en dos partes. Geometrizado así el movimiento el punto de curvatura de la senoide o eclíptica determina el proscenio, abocando al actor. El dramaturgo no sólo se ha movido equilibradamente en la pendularidad sino que, a veces, cuando el fortalecimiento del eje lo requería, ha colocado movimientos en su largo; como, por ejemplo ocurre en la presentación de Tisbea, en el arranque del diálogo del rey D. Alonso con D. Gonzalo en la jornada segunda, etc.

Este modo de hacer, aporta una convexidad óptica al plano del tablado y a los volúmenes físicos de los intérpretes, al mismo tiempo que desdice la plena propiedad de algunas acotaciones ${ }^{62}$. Cuando las acciones no vienen intrínsecamente expresadas en el verbo, no duda en remedarlas por medio de la capacidad extralinguística de la palabra, para lo

60. Ch.V. Aubrun: La comedia española (1600-1680), Madrid, 1968, pág. 143, propone que el incendio es verdadero, pero no es posible porque Tisbea sale de su cabaña -hasta donde se han acercado Coridón, Anfriso, Belisa, sin que atisben el fuego- lamentándose metafóricamente del fuego de amor, para volver a ella, seguida de los pescadores (vv. 1035, 1036, pág. 187). No tendría sentido, en una cabaña incendiada realmente, que se adentrasen en el siniestro; como tampoco, que de nuevo y desde el propio incendio volviera a salir a ras del tablado para arrojarse al mar (v. 1042, pág. 187)

6l. «Ausentarme es mi remedio... Pues que sea presto», «por la puerta del jardín, / duque, esta prisión se engaña», en Tirso de Molina: El vergonzoso... El burlador..., op. cit., pág. 161.

62. El estar ocupada la «zona fuerte» del tablado por la mesa y sillas -en la primer cena de D. Juan con la Estatua- impide lo precisado por la acotación; «(...Don Gonzalo hacia él...y al compás Don Juan, retirándose hasta estar en medio del teatro)», pág. 237. El avance de uno y la retirada del otro ocuparían dos puntos más delanteros del «en medio». 
que se vale del mimetismo naturalista, como facilitador de sentido a la acción, así como donador de realidad o vida al lenguaje. También se vale de repeticiones, ya sean orales, gestuales o corporales, si bien generalmente hace uso de la repetición con aquellas ocasiones en que el verbo escasea; tal acontece con D. Juan y su comportamiento en el banquete de bodas de Aminta ${ }^{6.3}$, o con las dos cenas de nobles entre el de Lebrija y el de Calatrava ${ }^{64}$.

Este instrumento de su técnica, la repetición, hila para con el de la anticipación o preparación. El Burlador, demonio u hombre endemoniado ${ }^{65}$, hace su presentación violentamente mediante una vicisitud o situación significante, sin que haya ningún anuncio previo, y la acaba de manera fulgurante en el episodio con que principia la obra. Fray Gabriel es muy consciente de las dotes y popularidad de que goza su primer actor, Roque de Figueroa ${ }^{66}$, lo que augura que los espectadores desde el primer momento, aún no conociendo al personaje, tengan la atención prendida en él; por consiguiente, prepara ya en su primer salida de escena (huida aérea) el fulminannte final de D. Juan casi al acabar de la comedia. La escapada por el balcón del huerto entre humo y polvo ${ }^{67}$, como expresa D. Pedro, es el ardid que presagia el crepitar de muerte último, donde el fuego paralelamente se une a estas dos señas de destrucción. Aquí la repetición cobra un valor antitético espacial, puesto que la primer caída fue aérea y la segunda subterránea.

Gracias a estos dos instrumentos de su técnica y a las dos violentas situaciones con que inaugura y finaliza la pieza, la acción discurre en lenta y paulatina progresión hacia la culminación de un clímax mágico y trágico, que sobrelleva yuxtapuesto o entrecruzado un ambiente de excitación, creado por la máxima intensidad conferida a la preparación de los comportamientos de la Estatua, desde que D. Juan nombrara: «me dé muerte un hombre...(muerto) ${ }^{68}$.

La fórmula estructural constante sobre la que descansa el quehacer de la comedia, integra dos factores, manejados en serie combinatoria y repetición en todas las jornadas. Uno, el constituido por diálogo+diálogo+coloquio+coloquio+diálogo ${ }^{69}$, y otro, por monólogo+diálogo+coloquio ${ }^{70}$, los cuales sufren sólo ligera variación, debido a la posición de la canción, en circunstancias excepcionales, según se efectúe en el «desde dentro» o en el «a vista». Si lo hace en el «desde dentro», suprime el último sumando del primer factor, colocándose allí, y si tiene lugar en el «a vista», hace permutar el factor (diálogo+monólogo+diálogo) ${ }^{71}$, situándose al final.

Las cualidades de Tirso: efectiva construcción técnica que sugiere una división en cinco jornadas ${ }^{72}$, manejo eficaz de la acción, entre otras, le permiten esa búsqueda

63. Se sabe su accionar, con posterioridad, por boca de Batricio (vv. 16-42, págs. 218, 219).

64. Las señas de la primera sirven de base para la repetición en la segunda (vv. 543-620, págs. 237-40).

65. «...pero pienso que el demonio / en él tomó forma humana», en Ibídem., pág. 159.

66. Ibídem., pág. 147.

67. «...pues que, vuelto en humo y polvo, / se arrojó por los balcones», en Ibídem., pág. 159.

68. Ibídem., pág. 227.

69. Versos 27-242 de la jornada primera, $81-515$ de la jornada segunda y 409-560 de la jornada tercera.

70. Versos 985-1044 de la jornada primera, 569-630 de la jornada segunda y 664-787 de la jornada tercera.

71. Versos 572-636 de la jornada segunda.

72. Por ejemplo, el entreacto de la jornada tercera, quizá debería ir colocado en los inicios de la canción con que se abren las bodas de Aminta y Batricio; es decir, a partir del verso 632 de la segunda jornada, con la consiguiente redivisión o reestructuración externa de toda la comedia. 
o tentativa, por unión combinada de unas y otras escenas, de una «escena» que alcance su objetivo final en su visión de conjunto. Objetivo que encuentra un básico apoyo en la versatilidad del vestuario y sus distintos tipos de escenas.

Al auxiliarse del valor extralingüístico de la palabra o del mimetismo naturalista, no excluye un esquematismo que complemente el figurativismo de la interpretación, como es el caso de la aparición de la Estatua o de los músicos; por otro lado, tan bien adecuados a la visión del corral que facilita Zabaleta ${ }^{73}$.

La escena, en esta tentativa de conjunto, es realista e ilusionista, porque la realidad que reconstruye, como la temática mítico-pastoril-piscitoria de la fábula, en su sentido amplio, es de naturaleza histórica ${ }^{74} \mathrm{e}$, incluso, intelectual o cultista. Es ilusionista, porque crea un espacio útil a la acción física del actor, al tiempo que autocontemplativo del poder de los Austrias ${ }^{75}$, y no es exigible que tal espacio se corresponda con un ambiente o paisaje detalladamente identificable o exactamente reconocible.

73. «...porque las comedias, ni se oyen sin los ojos, ni se ven sin los oídos. Las acciones hablan gran parte, y si no se oyen las palabras, son las acciones mudas», en Juan de Zabaleta: El día de fiesta por la manana y por la tarde, (ed. de C. Cuevas García), Madrid, 1983, pág. 322.

74. Don Juan Tenorio fue Repostero Mayor del rey don Pedro el Cruel, como puntualiza A. Rodríguez López-Vázquez : «Don Pedro y Don Juan» en El mito en el teatro clásico español, (Coor. por RUIZ RAMÓN, F. y OLIVA, C.), Madrid, 1988, pág. 192.

75. Un par de años antes de subir al poder, Felipe IV había visitado Portugal, como futuro rey, en 1619. Ahora, en su ascensión al trono, se le presentaba como uno de los mejores soportes para su política hegemónica continental. El fin de la tregua con los Países Bajos, en este año de 1621, presagiaba su ruptura, dado que los holandeses, en ese momento, actuaban «como si estuviesen en guerra» (DOMÍNGUEZ ORTIZ, A.: «El Antiguo Régimen: Los Reyes Católicos y los Austrias», en Historia de España, (2a ed.), vol. III, Alfaguara, Madrid, 1974, págs. 375), dañando a las posesiones ultramarinas y al comercio de especias portugués, al tiempo que a la actividad colonial mercantil hispana. Situación a la que se sumaba el contrabando del vellón, con el consiguiente aumento de la inflación. Esto hizo que, tanto el Consejo de Estado de Castilla como el Consejo de Portugal, presionaran para que no se renovase Ia tregua. La reanudación de las hostilidades no se hizo esperar, y una nueva guerra iba a descansar sobre las espaldas de una Castilla agotada, entre otras causas, por «la gran carga tributaria» (ELLIOT, J. H.: La España Imperial (1469-1716), (5 reed.), Madrid, 1979, pág. 356), a la que no ayudaban los otros reinos peninsulares, a pesar de que todavía estaban exentos de cargas, amparados por sus fueros. Solamente Portugal, incluso con barrerras aduaneras, sostenía una postura solidaria, al mantener a la baja las especias en una aproximación de «allanar el camino entre España y el gran mercado de Lisboa» (HAMILTON, E. J.: El tesoro americano y la revolución de precios en España (1501-1650), Barcelona, 1975, pág. 248.). No es de extrañar, por tanto, que Tirso presente allí, en Lisboa, la primer aparición del rey castellano y su diálogo (vv. 697-876 de la jomada primera), intercalada en el episodio de Tisbea. Si utiliza el anacronismo, la acción discurre durante el reinado de Alfonso Onceno, lo hace para aproximar distanciando; no en vano, las plazas que se mencionan al principio del diálogo, especialmente la primera, son lugares de recalado para las naves en ruta hacia Filipinas, ruta de las especias. La descripción de Lisboa, gracias a la capacidad fantaseadora de la palabra en el «a vista» que presenta el corral, transmuta en la imaginación los componentes escenotécnicos topicamente típicos del paisaje urbano de la capital portuguesa; de este modo, la ciudad, como lugar de la representación teatral, permite a los espectadores, a la sociedad, el que «tende a identificarsi nell'autocontemplazione indotta» (ZORZI, L.: Il teatro e la città, (2a ed.), Torino, 1977, pág. 63). Todo lo cual induce a privilegiar, en el propio espacio, el lugar real o ficticio, destinado al espectáculo; en este caso concreto autocontemplación del poder de los Austrias. Escenario del poder y del espacio cívico, que bajo la forma metafórica del lenguaje figurativo oculta criterios políticos, ya que el espacio urbano y el espacio escénico se transforman en el vínculo de enlace pueblo-público. Seguimos el calendario de estrenos que de la producción dramática tirsiana establece $\mathrm{M}$. Vitse (en su «El hecho literario», en Historia del teatro en España, (dir. por DÍEZ BORQUE, J. M.), vol. I, Madrid, 1984, pág. 603). Por lo que 
La coherencia en lo austero de su estética y en la precisión de su estructura hacen de este trabajo del mercedario un modelo de destreza en la técnica dramática.

se refiere a El burlador de Sevilla y convidado de piedra, situamos la fecha de estreno entre 1622-23, apoyándonos también con lo argumentado sobre el trabajo Fontana-Villamediana. 